\title{
EDUCATION IN WORLD CITIZENSHIP
}

$\mathrm{T}$ HE League of Nations Union has recently established a Council for Education in World Citizenship which held its inaugural meeting at Oxford during April 11-15. The meeting, which took the form of a National Conference of Local Education Authorities and Teachers, dealt with "Problems of Education To-day in Relation to World Settlement after the War".

Some obviously uninformed views are abroad concerning the raison d'être and work of the newly formed Council and it may be appropriate to say here something of the reasons that have led to its formation.

The Education Committee of the League of Nations Union was formed some twenty years ago to instruct children in the aims and activities of the League of Nations. Throughout its existence it has had official approval and has enjoyed the support of many influential and important bodies within the Empire. Junior branches of the League of Nations Union have been formed in schools throughout the country with the approval and support of the local educational authorities concerned, and it would need an article in itself to outline the other activities of the Education Committee in sending children to Geneva, in providing summer schools and camps, in arranging courses of lectures, in making contacts with the youth of other nations, in a hundred and one ways endeavouring to break down those barriers of nationalist feeling which have, alas, culminated in the tragedy which overshadows our world of to-day.

All this good work went on with apparent success for some eighteen years, despite the deterioration in international affairs which sueceeded what Dr. Gooch has called the "sunshine of Locarno". But of late years certain difficulties have become increasingly apparent. The League of Nations Union is, in its very essence, a policy-forming as well as an educational body. The Education Committee is, emphatically, not a policy-forming body-its functions are educational first, last and all the time.

Nevertheless, when the League of Nations Union found itself, on occasion, acting in opposition to the policy of the Government in office, this opposition was said (quite incorrectly) to be reflected in the policy of the Union's Education Committee, which was accused of dabbling in politics.

The issue was brought to a head by the Munich crisis of 1938, when many junior branches seceded, giving as their main reason that they wished to study international affairs without necessarily subscribing to the tenets of the League of Nations Union.

It seemed therefore desirable to form a council which, while being in general sympathy with the ideals which inspire and guide the work of the League of Nations Union, should have complete autonomy in the management of its affairs.

Hence the appearance of the new Council. Its objects are to foster mutual understanding and habits of co-operation between the peoples of the different countries and to take steps to ensure that students are trained in the principles of international co-operation, including the aims and activities of the
League of Nations, and the terms of its Covenant. To these ends the council will encourage and assist such teaching of school subjects as will lead to an understanding of world affairs, the growth of civilization, the chief characteristics of nations and of national governments, the factors that unite and the differences that divide nations and the responsibilities of citizenship ; will assist both students and teachers in studying the causes of war and the means whereby a more just and stable world order may be created; will seek to provide opportunities for pupils to appreciate the best in other peoples, and to make friendly contacts with boys and girls of other nations ; will seek to ensure that nothing in our colleges and schools shall arouse hatred and contempt of other peoples ; and will teach the principles of freedom and justice, co-operation and good faith as the foundations of the good society in the home, school, State and world community.

Here, surely, is a programme with which every lover of freedom and justice will find himself wholeheartedly in agreement.

The proposed membership of the Council is wide enough to absolve it from any charge of sectarianism. It includes representatives from practically every important educational body, most of the administrative bodies connected with education, adult educational associations, committees of the British Broadcasting Corporation, the British Film Institute and representatives of the Guides and Scouts movements.

The inaugural meeting's success was qualified by only one untoward happening. Prof. Susan Stebbing was forced to cancel, by reason of illness, her paper on "Training in Clear Thinking on Public Affairs". Otherwise, the meeting's success far exceeded the anticipations of the organizers. Syllabuses are notoriously dull, but the scope of the meeting is best indicated by a résumé of the titles of the addresses heard by the three hundred delegates who attended the conference. The opening address, on "World Citizenship ; the Growth of an Idea", was delivered on Thursday evening by the chairman of the Council, Prof. Gilbert Murray. On Friday a discussion on "The League of Nations ; what next ?" was opened by Mr. Noel-Baker. On Friday afternoon Mr. H. G. Wells and Prof. Allan Ferguson opened a discussion on "The Teaching of World Unity ; what is being done and what might be done in the schools". In the evening, Prof. C. E. M. Joad delivered an address on "Proposals for Federal Union". On Saturday morning, Señor de Madariaga, M. Jan Masaryk, M. Maheu (chief representative in Great Britain of the French Ministry of Information), Count Jean Balinski Jundzill (Deputy Director of the Polish Research Centre, London), Dr. Rudolf Olden (formerly assistant editor of the Berliner Tageblatt), Mr. A. C. F. Beales, Mr. Ivor Montagu and Mr. W. Arnold Forster took part in a round-table discussion on "Some Guiding Principle for the next Peace Settlement". On Saturday evening Miss Dymond (Principal of the Portsmouth Municipal Training College) presented a report on "The effects of the War on the Minds of Children". On Sunday afternoon, Miss Charlesworth presided over 
a conference on "The Work of the Council", and on Sunday evening the delegates were addressed by the Headmaster of Rugby (Mr. P. H. B. Lyon), who took as his subject "The Spiritual Foundations of World Citizenship". The final session of the Council, to sum up the work of the Conference, was held on Monday morning, and the concluding address was given by Mr. Kenneth Lindsay, Parliamentary Secretary to the Board of Education.

Throughout the meeting the addresses and discussions attained and preserved a high level of interest. The opening address by Prof. Gilbert Murray, with its insistence on the futility of any form of political or economic co-operation which is not backed by a real will to brotherhood-by an intellectual co-operation having a firm ethical basismarked a line of thought which dominated the subsequent proceedings of the conference and which emphasized at once the difficulties and hopes attending any advance towards world unity.

So, too, the Headmaster of Rugby in his Sunday evening address. Therein he deplored the tendency of modern teaching to over-emphasize the ethical, and to lay too little stress on the religious outlook. In internationalism shorn of the religious habit of mind there was little driving force, and "as sentiments grew wider they grew shallower". He urged that religious education should be regarded as a fundamental necessity.

Mr. Noel Baker's address was an eloquent plea for a strengthening of the terms of the Covenant of the League. The League had not failed, in any true sense of the word. It had many successes to its credit, and, where its machinery had apparently broken down, the reason was to be found in the fact that commitments had been undertaken, had not been repudiated, but had remained unfulfilled. The address provoked a lively discussion.

In the afternoon's session on the teaching of world unity, Mr. H. G. Wells was as stimulating and provocative as ever. The present state of affairs in the teaching world (in particular the meagreness of the resources which the teacher had at hand in the matter of encyclopædias, books and apparatus) came in for some vigorous criticism. World unity was a fact; war was civil war; the non-combatant had disappeared, and the neutral was fast disappearing; League and Federal notions might well lead to failure, in the latter case because federated blocs might result, leading to war on a larger scale. It should not, however, be impossible to bring into one world opposition the oppositions which existed in the governments of all civilized countries, and so to persuade sovereign States to relinquish the control of matters which otherwise they would not relinquish. From the point of view of the teacher, old-fashioned history should be replaced by the study of the science of human ecology, the relation of man to his external surroundings-- children should be taught, not by telling them little stories of kings and queens, but by showing them their relation to the world as a whole.

Prof. Ferguson pointed out that science teaching provided an ideal medium for fostering the international outlook, and for exhibiting some of the most important relations of the individual to the community of which he formed a part. They had heard much of the effect of the aeroplane and of other inventions and discoveries in annihilating distance, but there were other and hitherto rather neglected topics about which equally fascinating stories could be told. $\mathrm{He}$ instanced some of the details concerning the transport and storage of food, and the new and rapidly growing industry of plastics. As regarded the teaching of history, a little investigation had shown that many teachers in training colleges and in public and secondary schools were fully alive to the necessity for teaching the subject from the point of view of world history, and that experiments in the improvement of international understanding by way of camps, tours abroad, junior branches of the L.N.U., and exchanges of visits and of letters were by no means unknown. In the primary schools, too, the teaching of history had changed remarkably in recent years. Any widening of outlook must be based on accurate knowledge oriented by an emotional appeal.

Undoubtedly, high though its general level had been, the culminating point of the Conference was reached in Saturday morning's round table discussion, and the varied views and high qualities of statesmanship shown therein made a deep impression on the delegates. The prevailing impression left on the minds of many hearers was that, although some approaches to world unity may, on paper, seem preferable to others, yet, granted good will, almost any scheme would work; that the gravest task which faces the statesmen burdened with the responsibility of realizing any future proposals for peace is that of ensuring that the proposals shall be carried out in a spirit of mutual helpfulness; that hatred shall be reserved for the sin, rather than for the sinner; and, to that end, that the peace proposals shall be worked out in detail after an armistice period which might extend over a period of some years. The Polish speaker, in the course of a moving speech, suggested that in addition to the closer union of Britain and France which might be regarded as initiating a new world order, a similar union might be contemplated between Poland and Czechoslovakia.

Mr. Arnold Forster, who summed up the discussion, was not in favour of a long armistice, and suggested that four stages should be contemplated in the making of peace-a period of conversation, an armistice, a period for the drafting of the peace treaty, and, finally, a world conference at which the terms of a general settlement should be discussed.

Saturday evening's meeting, to which Miss Dymond presented a report on "The Effects of the War on the Minds of Children", evoked very general interest. The number of pupils who were the subject of experiment was 317 , and all were in the 12-year agegroup. Pupils were asked to write (without preparation) a half-hour essay on "Why we are at war with Germany'. There was a majority ( 62 per cent of the boys and 60 per cent of the girls) who stated clearly that the war was due to German aggression.

Asked, "Who is your favourite hero ?", the members of the group showed surprisingly little interest in the outstanding figures of the day. Mr. Chamberlain scored four votes, Mr. Churchill three. Most of the boys voted for Nelson and Drake.

There were few reactions to war-professions in the answers to the question, "What would you like to be when you grow up ?-none at all among the girls, unless a desire to take up nursing be correlated with the War.

Perhaps the most interesting and illuminating answers were those given to the question, "What was the most important day of your life?" Some 
11 per cent of the boys and 12 per cent of the girls who had been evacuated mentioned the day of evacuation or that of the outbreak of war. 'On the other hand, a very large number voted for the day on which they sat for the junior scholarship examination.

Asked to continue a story which began, "There was a loud bang, Pat's heart beat fast," the boys tended towards adventure stories not necessarily connected with the War, girls to air-raid stories.

To the question, "In what period of history would you have preferred to live ?", the majority answered "The present time", and the surprising reason given was, "Because it's more comfortable." A significant number of girls chose a period in which they could wear a picturesque dress.

A free-association test, in which the significant words were "bang, ship, enemy aeroplane, shell", showed a strong war connexion with 'enemy' and 'bang', and it is interesting to note that 'shell' often evoked associations with the sea-shore.

Generally, the investigation showed that the War has had a considerable but not an overwhelming effect on the minds of children.

The impression which the conference as a whole has left on the mind of the writer of this review of its work is that the future of any successful approach to world unity lies in the hands of the teachers, and primarily in the hands of those responsible for the training of our youth below the age of fourteen; that we must rid ourselves of the delusion that there is a ladder of education with the primary school on the lowest rung, and the university on the topmost, and must realize that by far the most important years of education are those passed in our primary and senior schools, and that what happens in later stages is a divergence, rather than a climb; that there is an urgent need for the raising of the status and for the broadening of the training of those destined to become teachers in elementary schools; that the education of such teachers should not be regarded as ending with their period of training, but that every encouragement should be given to their making contacts with the world of thought which lies outside their school ; that it is a desirable thing to teach school subjects from a point of view wider than that of mere nationalism, but that such knowledge must be exact, and must, moreover, be informed by spiritual forces supplied, indirectly, in the home as well as in the school; forces, too, which the teacher must experience in his own home and college ere he can make their influence felt by those whom he is later called upon to teach; that the council is fully alive to these considerations; and that the council will be on the high road to success if its subsequent deliberations are informed with as much knowledge backed with as high an enthusiasm as was shown at its inaugural meeting.

\section{ESKIMO OF LABRADOR*}

$I^{\mathrm{N}}$ the course of the Rawson-MacMillan Subarctic Expedition of the Field Museum (1927-28), Dr. W. Duncan Strong secured a large series of measurements and observations of living Labrador Eskimo and a small group of Montagnais-Naskapi Indians. When obvious mixed bloods and sub-adults are eliminated, the numbers were 137 Eskimo (58 males, 79 females) and 18 Indians (11 males, 7 females). Labrador Eskimo skeletons were also obtained, including thirty-two measurable skulls (17 males, 15 females), many with associated skeletal parts. Measurements made by Shapiro, Boas, Pittard, Duckworth and others have been added in this study. An unusual series is thus made available, comprising (1) an old stone grave series, pre-white, and earlier than 1770 ; (2) a mid-nineteenth century grave series (early Mission period); and (3) racent living (1880-1928).

The material is drawn from the Eskimo of the north-east coast of Labrador, a remnant of a population once extending to the Gulf of the St. Lawrence. While the influence of the Moravian Mission has been directed to the preservation of Eskimo culture and habits, adoption of Caucasian types of food appears to have introduced modifications of physique, especially in reduction of stature and in general bodily habit of fat.

In the investigation of the Eskimo of Labrador, the evidence of physical character must be invoked to

* Anthropometric Observations on the Eskimos and Indians of Labrador. By T. Dale Stewart. Material and Data collected by William Duncan Strong. (Anthropological Series, Vol. 31, No. 1) (Publication 462). Pp. 164 +16 plates. (Chicago: Field Museum of (Publication History, 1939.) $1 \cdot 75$ dollars. aid in the elucidation of the archrological question. Briefly and in very general terms, the archæological problem is to determine the relation in the cultural sequence of pre-Thule, the Dorset and Thule cultures, and recent Eskimo. The evidence of physical anthropology is subject to very definite limitations, not least owing to the absence of skeletal material to be assigned to the Dorset culture.

It would appear that the culture of the Labrador Eskimo was most closely related to that distributed over the central Aretic, but retained more of the Thule culture than has survived in the central regions proper (T. Mathiassen). The Thule culture in the eastern Arctic is present only on pre-contact sites, except for a group on Southampton Island. Although Thule is considered to be the original Eskimo culture of the eastern Arctic, evidence has been presented suggesting that Thule may have been preceded by the Dorset people, though possibly in some places contemporaneous (D. Jenness).

In north-eastern Labrador evidence has been found of an earlier stone culture with Eskimo-like stone ulus, ground slate points and chipped scrapers. It contains almost nothing of the bone, antler, ivory and steatite artefacts characteristic of Thule, Dorset, and Labrador Eskimo (W. D. Strong); and this leads to the suggestion that the Eskimo cannot have been in Labrador for more than four hundred years.

By fitting ethnological detail into this succession of eastern Arctic cultures extending back into the prehistoric, several theories of Eskimo origin and migrations have been formulated, in which the erucial difference is the position to be assigned to 